$8^{\text {th }}$ International Workshop on Simulation for Energy, Sustainable Development \& Environment

$17^{\text {th }}$ International Multidisciplinary Modeling \& Simulation Multiconference

ISSN 2724-0061 ISBN 978-88-85741-52-2 (C) 2020 The Authors.

DOI: $10.46354 /$ i3m.2020.sesde.004

\title{
Discrete Event Simulation for the Investment Analysis of an Offshore Wind Nodes Automatised Workshop
}

\author{
Adolfo Lamas-Rodríguez ${ }^{1}$, Inés Taracido-López² and Javier Pernas-Álvarez ${ }^{3}$ \\ ${ }^{1}$ Navantia, Ctra. de la Circunvalación s/n, Ferrol, 15403, Spain; Universidade da Coruña and UMI Navantia-UDC, \\ Campus de Esteiro s/n, Ferrol, 15403, Spain. \\ ${ }^{2}$ UMI Navantia-UDC, CIT Campus de Esteiro s/n, Ferrol, 15403, Spain. \\ ${ }^{3}$ UMI Navantia-UDC, CIT Campus de Esteiro s/n, Ferrol, 15403, Spain. \\ ${ }^{1}$ adolfo.lamasr@udc.es, ${ }^{2}$ ines.taracido@udc.es, ${ }^{3}$ javier.pernas2@udc.es
}

\begin{abstract}
An innovative use of Discrete Event Simulation (DES) in the optimisation of the investment analysis of a jackets nodes manufacturing process is proposed in this paper. Normally, if we carry out investment analyses by using spreadsheets, it may be difficult to take into account the variability of the process at issue in a dynamic fashion. However, if investment assessment methods are integrated into a discrete event simulator, results become much more realistic because non-economic factors such as production rate and stochastic variables like task times are being directly considered. This paper shows how an investment analysis of a new workshop for jackets nodes robotised welding can be enhanced when implemented in a discrete-event simulator. Eventually, an optimisation of the model is also performed by setting investment analysis parameters as target variables.
\end{abstract}

Keywords: Offshore Wind; Industry 4.0; Discrete Event Simulation; Investment Analysis; Optimisation.

\section{Introduction}

Currently, the use of Discrete Event Simulation (DES) to perform investment analyses has been limited to evaluating the effects of a certain investment in the project at issue. These DES models usually provide a large amount of information concerning the pros and cons of possible investments with regard to their impact in the manufacturing process, hence facilitating further decision-making processes on their feasibility.

However, the application of simulation to investment analysis as such has not yet been addressed. In this sense, the use of a 3D DES model that in addition to serve as a digital representation of the real process allows for an investment analysis and yields results in terms of NPV (Net Present Value) or IRR (Internal Rate of return) may come to be a great aid in decisionmaking.

Main methods currently used when calculating profitability of a given project are chiefly dynamic, by considering for instance the depreciation of capital over time, since they become more accurate. NPV and IRR are the most extended ones along with the Payback Period.

When it comes to software, Excel is probably the most popular tool for investment analysis. This spreadsheet includes a wide variety of financial functions that allow calculating the abovementioned profitability indicators and suchlike. Nevertheless, the biggest disadvantage of this tool is that results obtained may be unrealistic, since static calculations cannot consider process variability inherent to

(C) 2020 The Authors. This article is an open access article distributed under the terms and conditions of the Creative Commons Attribution (CC BY-NC-ND) license (https://creativecommons.org/licenses/by-nc-nd/4.0/). 
manufacturing. DES arises as an alternative capable of taking these influential factors into account.

In the context of the fourth industrial revolution, the so-called Industry 4.0, a company dedicated to the manufacture of offshore wind foundations has decided to invest in the erection of a new workshop for jacket nodes robotised welding. A Jacket structure is a welded tubular space frame consisting of vertical legs supported by a lateral bracing system. Further, nodes are required to safely transfer forces and moments between horizontally braces and vertical legs. As explained by PEMA (2020), the share of the cost of the foundation in proportion to the complete wind turbine installation is considerably higher than in onshore. Therefore, it is of vital importance to optimise every part of the foundation production flow so that all associated costs can be minimized. In this respect, automation of nodes welding may increase substantially the efficiency of jackets production.

Referring to Salzgitter AG (2020), the automation of the welding process leads to savings in production time and costs, while simultaneously improving product quality. Excellent quality is essential in the welds of nodes used in modern steel structures such as offshore wind jackets, where their reliability governs the strength and fatigue resistance of the complete structure. Various destructive and non-destructive tests (NDT) have shown significant superiority over conventional manual welding in both quality and productivity.

Being competitive in the offshore wind market is critical in a world where energy demand is increasing, and most of it is still met by burning fossil fuels which, in turn, produce large amounts of pollution. For this reason, Europe is exploring ways to become carbonneutral by 2050. To achieve this, we will have to transform our energy systems by replacing fossil fuels with renewable electricity across the economy (EWEA, 2019). Consequently and according to EWEA (2017), wind energy will be key to decarbonizing the power sector by 2050. Thus, by ameliorating nodes manufacturing we achieve an overall improvement in jackets production, which were the second most employed substructure in 2019 after monopiles (EWEA, 2020). Monopile structure is a foundation consisting of a single, generally large-diameter, structural element that supports the entire load of a large above-surface structure.

For this purpose, a discrete event simulation of the future workshop has been carried out in order to study, among other aspects, process productivity and workshop layout though the development of several scenarios.

Once productivity of automated workshop has been examined, an economic analysis of the investment becomes necessary. For that purpose, an algorithm for calculating investment analysis parameters is developed and implemented in the workshop DES model. This allows the evaluation of the investment with much greater precision than common methods used so far, as it considers factors such as the production rate, waiting times or transport. These parameters can be introduced in the optimiser as target variables so as to obtain the most profitable scenario for the company, both from a productive and economic point of view. Finally, another advantageous aspect is due to the 3D graphics capability of the employed DES software, which facilitates the understanding and study of different scenarios and results by a non-expert user.

Overall, a more accurate investment analysis can be performed, and the initial forecasted investment could be reduced by optimising both economic and production parameters at once. This approach may be of great interest to companies because it enables the risk of making an investment to be considerably reduced.

\section{State of art}

The use of DES in the analysis of the productivity of a certain manufacturing process or to evaluate the impact of an improvement in such process has increased over the recent years. However, no references have been found in which cash flow calculation and investment analysis are integrated and can be carried out by using a DES model. The following paragraphs provide a brief summary of the most relevant studies with regard to the use of DES and investment analysis.

Gołda, Kampa, \& Krenczyk (2019) makes a comparison between a human-operated and a robotoperated line, driven by an increasing use of automation and robotisation and by leveraging the DES ability to conduct experiments that cannot be performed in real manufacturing systems and could lead to improvement. In this sense, they obtain a $25 \%$ performance increase in the robotic manufacturing line compared to the manually operated one. Eventually, they explain that results achieved can be used for detailed designing of a manufacturing system and for economic analysis, regarding labour costs and costs associated with the investments due to robotisation.

Freiberg \& Scholz (2015) evaluates operating parameters of new manufacturing equipment and its financial impacts. They use DES to make decisions on investments in advanced manufacturing technologies, by performing more accurate and faster analyses and quantification of various options. As they explain, the final decision should not be based only on economic calculations, but should also consider other benefits such as productivity, capacity utilization, faster product delivery, flexibility, quality and so forth.

Barrios et al. (2008) aims to describe the main characteristics of DES and the advantages of these models with respect to other kinds of simulations in health economics, especially in the evaluation of health technologies and product assessment. They examine a 
process with patients with cardiovascular disease for which two types of pacemakers can be implanted: VVI (R) or DDD (R). Patients walk through the model during the clinical study so that the costs associated with the use of resources involved in it are tracked. As a result, an additional cost is observed in patients implanted with double chamber pacemakers (DDD (R)).

In Widjaja \& Tsai (2019), three different types of crude oil transfer operations and their combination were analysed using discrete event simulation so that the project-specific key performance indicators can be evaluated. Results of this study allowed the project stakeholders to identify the benefits and disadvantages of investing in different types of infrastructure, as well as identifying the port's competitiveness with other port facilities in the region.

Sislioglu, Celik, \& Ozkaynak (2019) proposes a model to decide optimum investment alternatives to improve CT (Container Terminal) productivity. The proposed approach incorporates the parameters such as number of quay cranes, total length of a quay, yard trucks and yard cranes. The objectives of the model are minimizing the average ship turnaround time while maximizing the container throughput generated by the terminal. The methodology behind the model includes Discrete Event Simulation Model, data envelopment analysis (DEA) and cost-efficiency analysis.

In relation to offshore wind industry, the use of DES is also flourishing. Some of the most relevant papers in this field are mentioned below.

Lamas-Rodríguez, Crespo-Pereira, \& SánchezTutor (2016) develops several DES models to minimize flowtime per jacket, optimise workstations' utilization and decrease buffers' length as well as considering manufacturing costs expressed in terms of working hours. Furthermore, this paper highlights how useful DES becomes to evaluate the effect of taking certain simple measures in processes, which further allow companies to increase their profitability without involving too much investment.

Lamas-Rodríguez, Chas-Álvarez, \& Muiña-Dono (2017) presents an innovative parametric tool for quantifying project risks by applying DES. In particular, they refer to risks associated with delays in the supply chain and customer's AFC (Approved For Construction) drawings delays in the context of an offshore wind foundations manufacturing project. They remark the importance of properly analysing risks under different aspects and how a good risk management methodology can help to finish the project successfully.

Lamas Rodríguez, Chas Álvarez, \& Muiña Dono (2019) presents a tool based on 3D DES that allows evaluating the internal logistic strategy for the Transportation and Load-Out operations in an offshore wind project in terms of costs and resources. This paper focuses on the usefulness of 3D DES model to evaluate costs, develop new storage and assembly strategies, and eventually bring commercial value onto the project, allowing the company to verify its feasibility.

\section{Manufacturing process of a jacket node}

Currently, manufacturing process of a node roughly consists in assembling a variable number of stubs, depending on the type of node, and a central chord by means of manual welding, Figure 1.

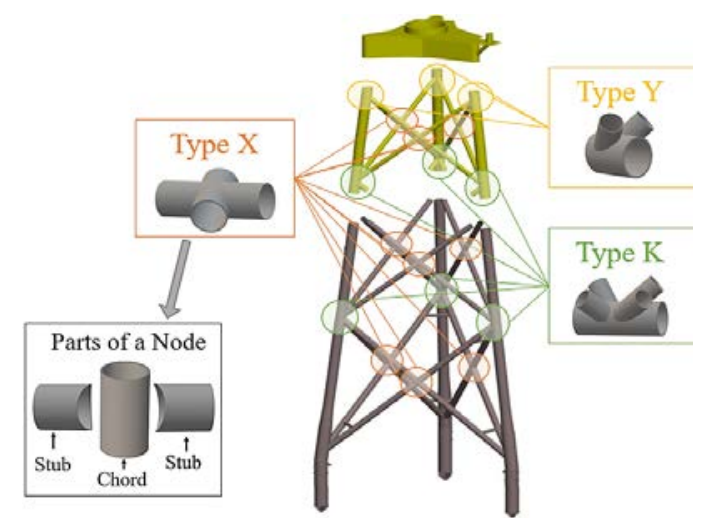

Figure 1. Types and Parts of Nodes.

A supplier provides nodes components with their respective cutting and edge preparation. Although supplied material meets pre-established tolerance, in a high percentage of nodes small variations in the curvature or a too much pronounced edge cause assembly operations to be halted and defects to be corrected. This issue results in increases in both production time and cost, so it may also yield significant delays and bottlenecks in the overall jackets manufacturing.

In order to face this problem, in addition to the welding robot and other already defined improvements, a stub edge preparation and cutting station will be implemented in the future jacket nodes robotised welding workshop. This station will be placed at the beginning of the process to reduce the likely impact of stubs edge defects in downstream activities and, in particular, in the robot.

\subsection{Types of nodes}

A jacket is composed of a total of 18 nodes: $3 \mathrm{Y}$-nodes, $6 \mathrm{~K}$-nodes and $9 \mathrm{X}$-nodes, as shown in Figure 1. The characteristics of each type of node are summarized in Table 1.

Table 1. Welding Volumes and Weights according to the type of node.

\begin{tabular}{lll}
\hline Node & $\begin{array}{l}\text { Approx. Weight } \\
(\mathrm{t})\end{array}$ & $\begin{array}{l}\text { Approx. Weld Volume } \\
\left(\mathrm{cm}^{3}\right)\end{array}$ \\
\hline $\mathrm{Y}$ & 2.2 & 1,890 \\
$\mathrm{X}$ & 5.2 & 4,380 \\
$\mathrm{~K}$ & 15.3 & 7,080 \\
\hline
\end{tabular}

\subsection{Case Description}

In the present, nodes manufacturing is subcontracted to several local companies. Therefore, in the search of a 
cost reduction in the long-term, the company has considered the possibility of taking over their fabrication by building a nodes robotised welding workshop which, in turn, will automate the process and improve its efficiency.

From previous R\&D projects, like JaCo (CARBON TRUST, n.d.), a node welding robot is already available. It is capable of manipulating nodes while performing the welding, although the root pass must be done earlier outside of the robot. The robot deposition rate may be up to 7 times the manual deposition rate while decreasing the rate of welding defects. The existence of the robot means that a great part of the investment has already been undertaken.

One aspect to bear in mind is that due to its design, the robot can only weld X-nodes and Y-nodes. As a consequence of their weight and dimensions, $\mathrm{K}$ nodes have to be manufactured by other suppliers.

Process flow diagram of robotised welding workshop is shown in Figure 2.

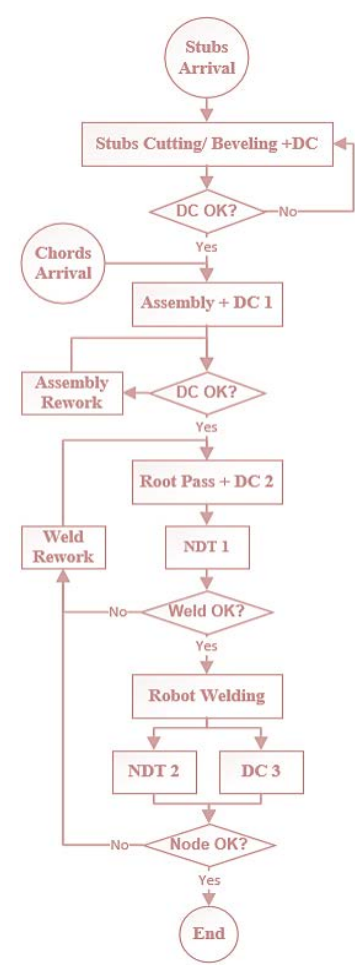

Figure 2. Process Flow Diagram of Robotised Welding Workshop

\section{Methodology}

Uncertainty is one of the biggest problems that companies must face when making an investment. DES facilitates decision making by analysing multiple scenarios at once though dynamic and stochastic simulations.

For this reason, DES has been considered a very suitable tool in the evaluation of investments, from both a productive and an economic point of view.

\subsection{Robotised workshop simulation model}

The software chosen to develop the jacket nodes robotised welding workshop DES model is FlexSim. This selection was made based on the grounds that the personnel had experienced with FlexSim, as well as of the Process Flow tool provided by this software, which significantly improves both the modelling and debugging task.

The first objective of the study was to obtain a design of the layout and the requirements of the robotised workshop so that it meets the takt-time of 1 jacket ( 9 $\mathrm{X}$-nodes and $3 \mathrm{Y}$-nodes) per week.

Different scenarios were examined, and further optimisation was carried out regarding the number of resources used in them while fulfilling the takt-time. In the best scenario, the workshop is able to produce all $\mathrm{Y}$ nodes and $\mathrm{X}$-nodes of a jacket with an average time of 4.88 working days, considering a two-shift schedule and a total of 11 workstations and 17 operators, as shown in Table 2 .

Table 2. Result of the Best Scenario
\begin{tabular}{ll}
\hline Y/X Assembly Workstations & 5 \\
\hline Y/X DC 2 and DC 3 Workstations & 6 \\
\hline $\begin{array}{l}\text { Assembly, Welding, NDT, DC } \\
\text { Operators }\end{array}$ & $\mathbf{1 3}$ \\
\hline $\begin{array}{l}\text { Output (Working Days / Jacket } \\
\text { Nodes) }\end{array}$ & $\mathbf{4 . 8 8}$ \\
\hline $\begin{array}{l}\text { Operators reduction with respect to } \\
\text { manual }\end{array}$ & $\mathbf{4 1 \%}$ \\
\hline $\begin{array}{l}\text { Stations reduction with respect to } \\
\text { manual }\end{array}$ & $\mathbf{2 3 \%}$ \\
\hline
\end{tabular}

This scenario achieves a significant reduction in resources with respect to the manual manufacturing of nodes, with a reduction of $41 \%$ in the number of operators and $23 \%$ in the number of stations.

The following images, Figure 3 and Figure 4, show the final approach for the robotised workshop layout.

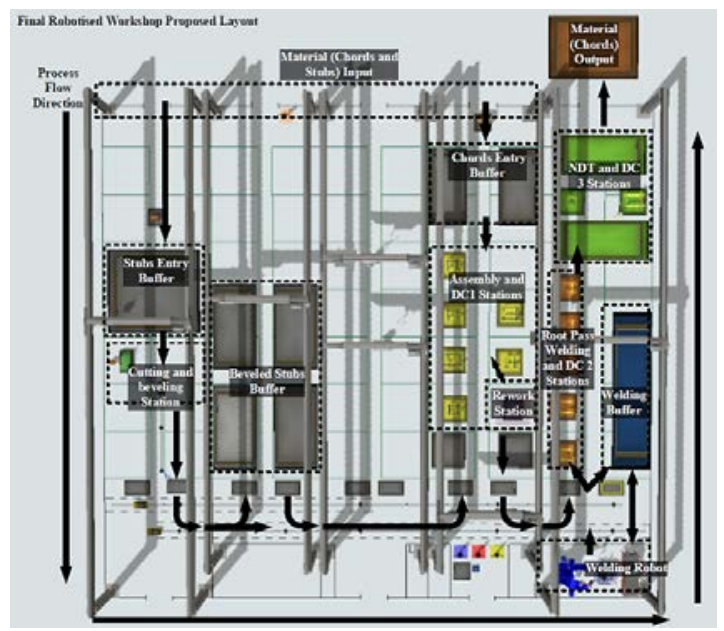

Figure 3. FlexSim Model of the Robotised Welding Workshop Layout. 


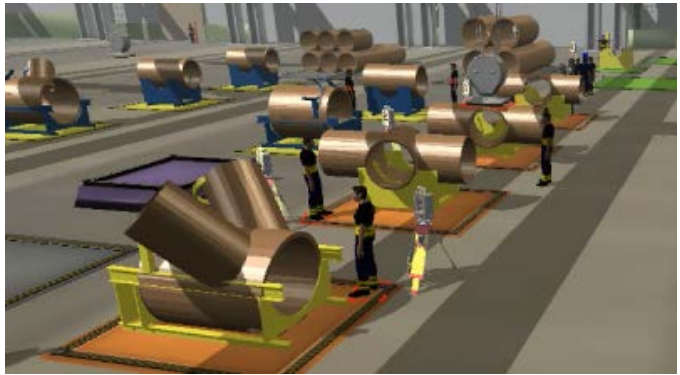

Figure 4. Screenshot of FlexSim Model.

Therefore, the results obtained are in accordance with the expected $30 \%$ of cost reduction in offshore foundations manufacturing.

\subsection{Problem description}

So far, the investment analysis is carried out following the company's internal regulations, that is, the investment authorization and the respective control regulations, in conformity with the Royal Decree 1514/2007, of November 16 (BOE-A-2007-19884) and IFRS (International Financial Reporting Standards). This stipulates that, for this type of project, the investment analysis is calculated on savings per node, namely the difference in the cost of manufacturing a node between using manual and robotic welding. With this value along with the number of nodes that are manufactured in a year, a saving per year can be obtained which is assumed to be constant over 10 years.

Once the value of the investment and the annual savings have been estimated, the calculation of Cash Flow, NPV, IRR and Payback Period on Investment is done using Excel tools. Finally, results are discussed and analysed to know whether the project is economically viable for the company.

As already stated in the introduction of this paper, this method of analysing an investment does not include various aspects such as process variability or waiting times. This may result in higher risks and imply that decisions do not always rest on firm foundations.

This is the main reason why a DES model has been used here to obtain a more reliable investment analysis with a higher level of confidence.

In this respect, in the Case Study 1 the robotised workshop FlexSim model was first used to obtain the cost of automating nodes manufacturing and then perform the subsequent investment analysis by using Excel. A further step was taken in the Case Study 2, in which the calculation of investment parameters was directly implemented in the model. In the following sections, both cases are examined in greater detail.

\subsubsection{Case Study 1: Using DES and Excel}

As a first approach, the DES model of the robotised workshop was modified so that as the months go by in the simulation, the total monthly cost entailed by the operators is computed and written on a table. Once the simulation has finished, the table is automatically exported to an Excel spreadsheet which eventually performs the investment analysis with the data retrieved by the FlexSim model.

\subsubsection{Case Study 2: Using DES}

With the objective of performing the investment analysis as the simulation time elapses and finally optimising the model by considering the investment parameters, Case Study 2 was developed. An algorithm was first created within the model capable of calculating cash flow, NPV and IRR. The investment value calculation, which depends on the effective number of workstations within the model, was also integrated at the start of the simulation.

Once the model was validated, an optimisation was carried out by considering takt-time, investment amount, NPV and IRR as target variables. The goal was to achieve a model in which with the minimum possible investment, a takt-time of not more than 5 working days per jacket nodes and acceptable values of NPV and IRR are obtained.

\section{Experimental results}

The production of nodes over a period of 10 years has been considered to obtain results. During this period, several interspersed projects of 62 and 35 jackets were programmed.

\subsection{Using DES and Excel}

As previously stated, in the first case study the investment analysis was based on savings and carried out according to the company's methodology, where the DES model provides Excel with the input data.

In this sense, before anything else, it was necessary to estimate the cost of subcontracting the manufacture of nodes, manually done so far. To accomplish this, several offers received by the company in previous projects were collected and examined, with the respective transportation costs in addition.

On the other hand, the cost of robotised manufacturing was exported directly from the DES model. To work out this value, it was necessary to introduce in the model the hourly cost of an operator as well as implement a code in charge of doing the calculation on a monthly basis, in concert with the hours worked, and by taking into account both shifts and the number of active operators.

Once the model was validated and run, the results were exported to Excel. Here, the annual savings were obtained from the difference between the cost of manual and robotic manufacturing. Afterwards, we determined the cash flow and the rest of the investment analysis parameters.

Table 3 and Figure 5 summarize the results of the investment analysis performed in the first case study. 
Table 3. Investment Analysis from the First Case Study.

\begin{tabular}{|r|c|c|c|c|c|c|c|c|c|c|c|}
\hline \multicolumn{10}{|c|}{ INVESTMENT ANALYSIS - T=10 year - (values in M€) } \\
\hline & $\mathbf{2 0 2 0}$ & $\mathbf{2 0 2 1}$ & $\mathbf{2 0 2 2}$ & $\mathbf{2 0 2 3}$ & $\mathbf{2 0 2 4}$ & $\mathbf{2 0 2 5}$ & $\mathbf{2 0 2 6}$ & $\mathbf{2 0 2 7}$ & $\mathbf{2 0 2 8}$ & $\mathbf{2 0 2 9}$ & $\mathbf{2 0 3 0}$ \\
\hline INVESTMENT & 1.95 & & & & & & & & & & \\
\hline SAVING & 0.00 & 0.74 & 0.71 & 0.74 & 0.70 & 0.74 & 0.70 & 0.74 & 0.70 & 0.74 & 0.73 \\
\hline $\begin{array}{r}\text { CUMULATIVE } \\
\text { SAVING }\end{array}$ & 0.00 & 0.74 & 1.45 & 2.19 & 2.90 & 3.63 & 4.33 & 5.07 & 5.77 & 6.51 & 7.24 \\
\hline CASH FLOW & -1.95 & 0.74 & 0.71 & 0.74 & 0.70 & 0.74 & 0.70 & 0.74 & 0.70 & 0.74 & 0.73 \\
\hline $\begin{array}{r}\text { CUMULATIVE } \\
\text { CASH FLOW }\end{array}$ & -1.95 & -1.21 & -0.50 & 0.24 & 0.95 & 1.68 & 2.38 & 3.12 & 3.82 & 4.56 & 5.29 \\
\hline CPI & $2 \%$ \\
\hline NPV & 4.55 M€ \\
\hline IRR & $35.43 \%$ \\
\hline \hline
\end{tabular}

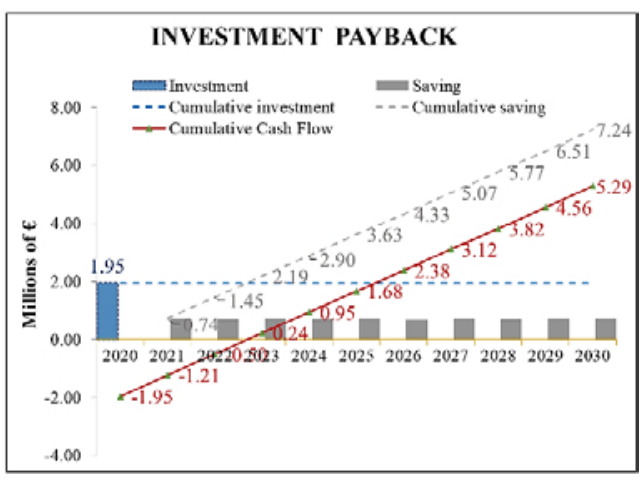

Figure 5. First Case Study Investment Payback Graph.

In the light of the results, the investment turned out to be profitable for the company. Since NPV is positive and quite high, 4.55 million euros, so becomes the IRR, which is above $30 \%$. Furthermore, the graph shows that in the course of 3 years and 8 months the investment should be entirely recovered.

According to the objective of this study, we drawn a comparison between the results that the company had obtained by applying its internal regulation in Excel (SCENARIO 1), and those we go by using the FlexSim model as the input (SCENARIO 2). Table 4 and Figure 6 illustrates this comparison.

Table 4. Comparison of Results between Scenario 1 and Scenario 2.

\begin{tabular}{|r|c|c|}
\cline { 2 - 3 } \multicolumn{1}{c|}{} & Excel & FlexSim and Excel \\
\cline { 2 - 3 } \multicolumn{1}{c|}{} & $\begin{array}{c}\text { SCENARIO 1 } \\
10 \text { years } \\
13 \text { operators }\end{array}$ & $\begin{array}{c}\text { SCENARIO 2 } \\
10 \text { years } \\
17 \text { operators }\end{array}$ \\
\hline NPV & $8.86 \mathrm{M} €$ & $4.55 \mathrm{M} €$ \\
\hline IRR & $61.17 \%$ & $35.43 \%$ \\
Payback & 2 years & 3 years \\
Period & 5 months & 8 months \\
\hline
\end{tabular}

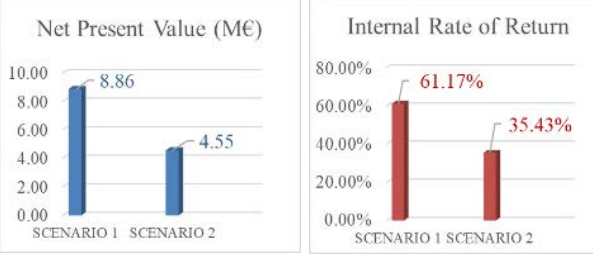

Figure 6. NPV and IRR Graphs for Scenario 1 and Scenario 2.
Although in both scenarios the investment came to be profitable, the values became much worse when the input data relied on the DES model. We conclude that it is because some of the estimates made in scenario 1 were not completely accurate. The truth is that obtaining an investment analysis of a future project is a complex task, and even more so when it comes to setting up an entire workshop along with the technologies involved, which is the present case. However, thanks to DES it has been possible to study and validate the layout, as well as to estimate process times and the number of operators and stations needed with a certain degree of confidence. All this becomes of great value in providing a solid starting point for economic analysis.

All the aforementioned was clearly reflected in this first case. While in scenario 1, 13 operators had been estimated to be needed in the workshop, by means of the DES model we nevertheless verified that this figure actually increased up to a total of 17 operators. This fact together with other factors such as task times and material arrivals significantly worsened the investment in scenario 2 .

It is worth noting that there may be cases in which a certain investment which initially was believed to be profitable becomes loss-making. If so, DES may be the key to the good performing to the company.

\subsection{Using DES}

Once studied how DES can improve the investment analysis functioning as the source of information, we went one step further by implementing the calculation right within the DES model.

In this respect, first the necessary data for the calculation such as costs, CPI (Consumer Price Index) and data on manual manufacturing was collected and introduced in the model. Then, we developed and implemented an algorithm for NPV, IRR and Payback Period calculation by using the Process Flow tool. Turning to details, in the case of IRR, succeeding approximations approach and a pre-defined difference were used to work out the result.

When it comes the simulation, at the beginning the investment is calculated according to the number of workstations and operators that will be employed in the run. This means that if the number of stations is modified, so too will the value of the investment, just as it would happen in the reality, which directly affects the analysis of the investment.

Other aspects considered were the number of works shifts and the forecast of company projects. Moreover, by entering data on a FlexSim table or importing them from an Excel spreadsheet, the user can easily vary these parameters and check their impact in the investment analysis.

The validation of the model has been carried out, on the one hand, by validating the model by planning 
personnel and verifying that the production rate is that required by the shipyard and, on the other hand, checking the results of the investment analysis and validating them by the company strategy management.

After validation, several simulations were run while varying the amount and timing of forecasted projects. Table 5 shows the results of the scenarios considered in FlexSim.

Table 5. Results obtained in FlexSim from Different Project Schedules.

\begin{tabular}{|r|c|c|}
\cline { 2 - 3 } \multicolumn{1}{c|}{} & \multicolumn{2}{c|}{ Using FlexSim } \\
\cline { 2 - 3 } \multicolumn{1}{c|}{} & $\begin{array}{c}\text { SCENARIO 2 } \\
\text { 10 years } \\
17 \text { operators }\end{array}$ & $\begin{array}{c}\text { SCENARIO 3 } \\
2 \text { years } \\
17 \text { operators }\end{array}$ \\
\hline NPV & $4.55 \mathrm{M} €$ & $-0.54 \mathrm{M} €$ \\
\hline IRR & $35.43 \%$ & $-17.73 \%$ \\
\hline $\begin{array}{r}\text { Payback } \\
\text { Period }\end{array}$ & $\begin{array}{c}3 \text { years } \\
8 \text { months }\end{array}$ & $\begin{array}{c}- \text { years } \\
- \text { months }\end{array}$ \\
\hline
\end{tabular}

To start with, scenario 2 considered the same calendar as the one studied in the previous section, in which a 10-year project schedule had been established. The results of this case allowed us to validate the integration of the investment analysis with FlexSim by verifying that they were of the same order of those obtained with Excel in the previous section.

Scenario 3 studied the current contractual scheduling of the company, which consists of several projects which have a total duration of 2 years. As expected, the payback on investment cannot be produced at this time. Focusing on the NPV and the IRR, the values have been negative, which is also an indicator that the investment does not recover and is not profitable if you only expect to have a workload for 2 years. Therefore, it can be concluded that it is necessary for the company to ensure a workload of at least 3 years and 8 months to pay off the investment.

In order to demonstrate the solidity of the results, 50 executions of each scenario have been carried out. Defining a $95 \%$ confidence interval the mean output values are:

- Scenario 2: $\mathrm{NPV}=4.52 \mathrm{M} €$ and $\mathrm{IRR}=35.38 \%$

- Scenario 3: $\mathrm{NPV}=-0.54 \mathrm{M} €$ and $\mathrm{IRR}=-17.71 \%$

Each red dot in Figure 7 corresponds to the NPV value obtained in each of the 50 replicas, in scenarios 2 and 3 respectively.
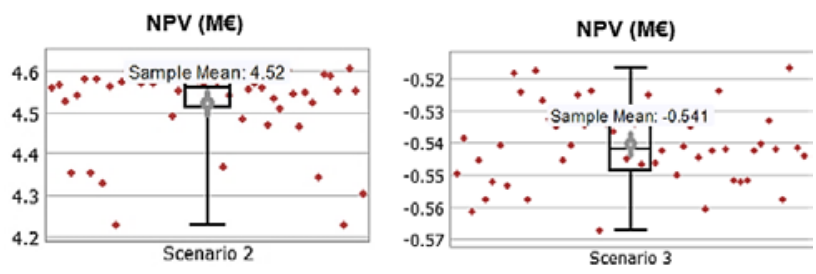

Figure 7. NPV results obtained in the 50 replicates of scenarios 2 and 3.

\subsubsection{Interface Development}

With the aim of facilitating the use of the model and the interpretation of the results by non-expert users, we developed very intuitive input and output interfaces.

The input interface was developed to modify the model parameters and carry out different experiments, as shown in Figure 8. Through it, the user can easily edit processes durations, the number of workstations, capacity of queues, defects rates or input data from the Investment Analysis.

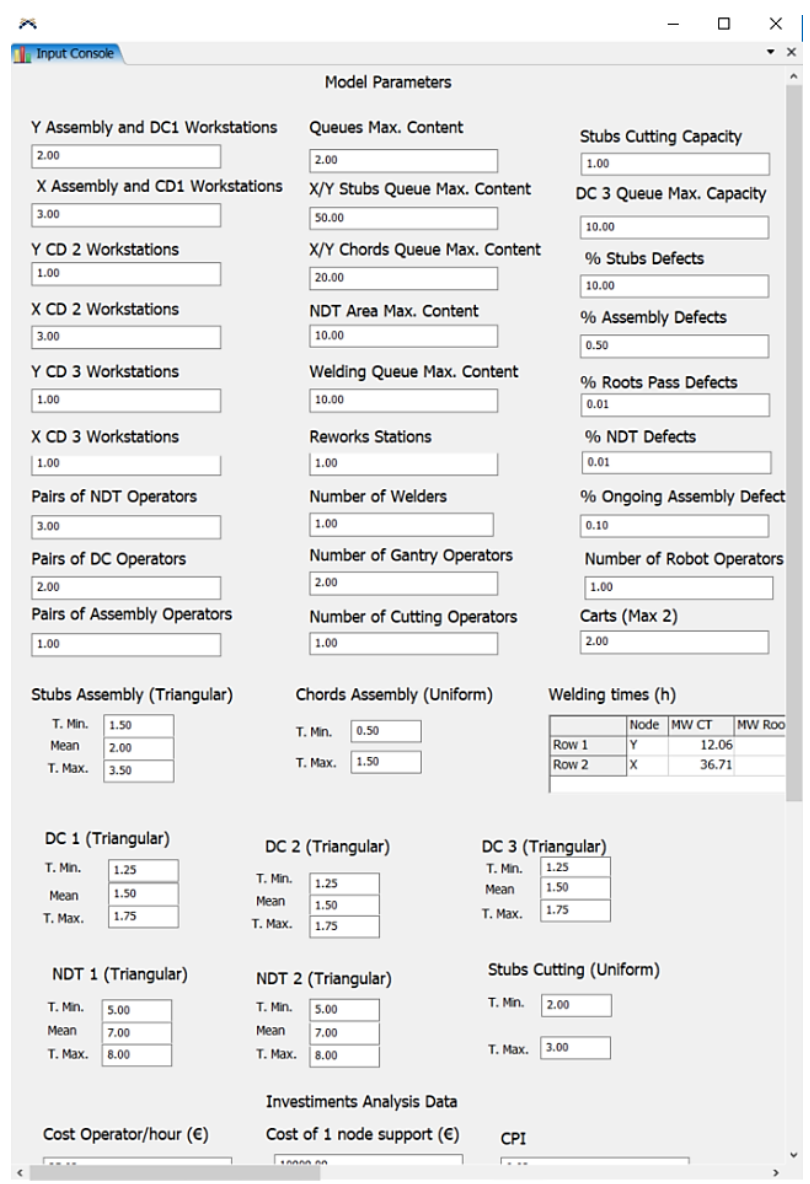

Figure 8. Model Input Interface.

When it comes to the outcomes of the investment analysis, an output interface was also developed, as shown in Figure 9. In it the calculation of the annual cash flow is displayed by means of a table, where the columns correspond to the years passed, so it is completed as simulation time elapses. In the same way, as time advances, the values of the NPV, IRR and payback period are also updated. These are eventually shown in the output interface as well. 


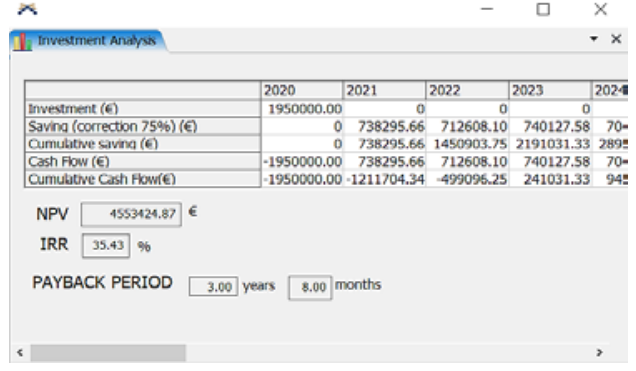

Figure 9. Model Output Interface.

\subsubsection{Model optimisation}

An important advantage of implementing investment analysis in the DES model is being able to use these parameters in the FlexSim Experimenter and Optimiser.

To end this study, an optimisation of the model parameters has been performed using the OptQuest optimiser provided by FlexSim. The number of workstations and operators have been introduced as variables. In turn, the optimisation objective had been to analyse takt-time, investment amount, NPV and IRR. In a productive context, the objective was to meet the activity time of one jacket ( $9 \mathrm{X}$ nodes and $3 \mathrm{Y}$ nodes) per week ( 5 business days).

After optimisation and studying different scenarios in the experimenter, we have made a selection of the most relevant scenarios in this study. The following table, Table 6, contains the description of these scenarios and the one previously studied, scenario S2.

Table 6. Scenario Description.

\begin{tabular}{|c|c|c|c|c|c|c|}
\hline Scenario & $\begin{array}{c}\text { Y and X } \\
\text { Assembly } \\
\text { Workstations }\end{array}$ & $\begin{array}{c}\text { Y and X } \\
\text { DC 2 } \\
\text { Workstations }\end{array}$ & $\begin{array}{c}\text { Assembly } \\
\text { Operators }\end{array}$ & $\begin{array}{c}\text { Welding } \\
\text { Operators }\end{array}$ & $\begin{array}{c}\text { DC } \\
\text { Operators }\end{array}$ & $\begin{array}{c}\text { NDT } \\
\text { Operators }\end{array}$ \\
\hline S2 & 5 & 4 & 2 & 1 & 4 & 6 \\
\hline O1 & 5 & 5 & 4 & 2 & 4 & 6 \\
\hline O2 & 5 & 3 & 2 & 2 & 4 & 6 \\
\hline O3 & 6 & 4 & 2 & 1 & 2 & 6 \\
\hline O4 & 5 & 4 & 4 & 2 & 2 & 6 \\
\hline
\end{tabular}

Similarly, Table 7 shows the results of each of these scenarios. If we focus on the working days per jackets nodes column, all the values are less than 5 days except scenario 02. The choice of this scenario is encouraged because despite subtly exceeding the expected takttime, the value of the investment is decreased and the IRR is close to $30 \%$.

Table 7. Results of Scenarios.

\begin{tabular}{|c|c|c|c|c|}
\hline Scenario & $\begin{array}{c}\text { Working } \\
\text { Days/Jacket } \\
\text { Nodes }\end{array}$ & $\begin{array}{c}\text { Investment } \\
\text { (M€) }\end{array}$ & NPV (M€) & IRR (\%) \\
\hline S2 & 4.88 & 1.95 & 4.56 & 35.5 \\
\hline O1 & 4.67 & 1.96 & 2.31 & 20.12 \\
\hline O2 & 5.07 & 1.94 & 3.13 & 26.78 \\
\hline O3 & 4.86 & 1.96 & 6.43 & 46.95 \\
\hline O4 & 4.68 & 1.95 & 4.1 & 32.23 \\
\hline
\end{tabular}

Analysing the investment column, we can see that there are scenarios in which the amount exceeds the expected 1.95 M€. But where we really find more disparity in the results of the investment analysis, in the last two columns. It is important to note that in all scenarios NPV and IRR are positive, indicating that the investment is profitable. However, the criteria to accept an investment depend on firms, in our case the company considers it necessary to have an IRR of around or above $30 \%$.

The results of scenario $\mathrm{O} 1$ and scenario $\mathrm{O}_{4}$ do not show any improvement compared to the initial scenario, therefore they are discarded. In the case of scenario $\mathrm{O} 2$, the amount of the investment is reduced, however, this causes the manufacturing time of the nodes of a jacket to be increased to 5.07 and the IRR is somewhat less than optimal. On the other hand, in scenario 03 the IRR increases with respect to that of scenario S2, although this is due to an increase in the value of the investment.

Scenario $\mathrm{O}_{3}$ is ruled out if we do not want to exceed the investment budget. Therefore, the decision is between scenario $\mathrm{S} 2$ and scenario $\mathrm{O} 2$. If the objective of the company is to comply with the takt time of 5 working days to manufacture the nodes of a jacket and obtain an IRR greater than $30 \%$, the scenario optimum is S2. However, if obtaining a lower investment prevails over the other factors, the best scenario is $\mathrm{O} 2$.

It is important to note that the requirement to obtain an IRR of around $30 \%$ was requested when the investment analysis was not carried out using DES. As it has been seen previously in Table 4 and Figure 6, when using DES the information is more accurate and the results more real, so perhaps it is not necessary to require an IRR of $30 \%$. In any case, in scenario 02 , the IRR is quite close to this value. At the same time, the value of the working days / jackets nodes of 5.07 is slightly higher than 5 , but this could be easily solved by advancing the start of manufacturing if necessary. We can conclude, therefore, that scenario $\mathrm{O} 2$ can also be a very interesting option. For this reason and to demonstrate the robustness of the results, we have carried out 50 runs of the $\mathrm{O} 2$ scenario, from which the following mean values have been obtained for a $95 \%$ confidence interval:

- Working Days/Jacket Nodes $=5.09$

- $\mathrm{NPV}=3.17 \mathrm{M} €$

- $\mathrm{IRR}=26.97 \%$

The final decision is in the hands of the company, which must evaluate whether it is worth selecting the initial scenario, S2, or if, by contrast, it compensates decrease investment, adapting to a subtle increase in takt -time and an IRR of $26.78 \%$, scenario 02 .

\section{Conclusions}

The innovative use of 3D discrete-event simulation in the investment analysis of a workshop for jackets nodes robotised welding was presented in this paper.

First, the investment analysis was calculated 
following the company's methodology in a spreadsheet. After this, the calculation was improved thanks to the information extracted from the DES model of the workshop for jackets nodes robotised welding. And finally, a further step was taken by implementing the investment analysis in the discrete event simulator so that it could be calculated as the simulation time wore on. In this way it allowed to modify the scheduling of the projects and see how it affected the profitability of the investment, and even optimise the model by introducing model and investment parameters as target variables. This made it possible to study and obtain scenarios with lower investment values for the same productivity outcomes.

Furthermore, a very intuitive input interface was also created so that a non-expert user can modify model parameters and examine different scenarios. Similarly, an exit interface was developed to display the results of the investment analysis in a clear way.

In addition to all the advantages inherent to having a digital twin of a process, the use of DES for investment analysis in our case has stood out for

- Incorporating variability in the investment analysis process.

- The versatility to studying different scenarios simultaneously.

- Having a parametric model: it allows the easy modification of almost any process or investment parameter and to see its impact in the profitability and feasibility of the case.

- Strongly improving communication and understanding of results thanks to the friendly interface and 3D visualization.

All in all, the present study demonstrates that the use of DES for investment analysis reduces risks and increases the robustness of results. Normally, with the use of spreadsheets, it is not possible to consider noneconomic factors such as variability or times to failure, which with DES can be directly considered to check its influence in either economic or production results.

For all these reasons, this application arouses great interest for companies which might consider applying it to their future investments.

\section{Acknowledgements}

The authors are thankful to the joint venture NavantiaUniversity of A Coruña (UMI) and Navantia for their valuable support.

\section{References}

Barrios, J. M. R., Serrano, D., Monleón, T., \& Caro, J. (2008). Los modelos de simulación de eventos discretos en la evaluación económica de tecnologías y productos sanitarios. Gaceta
Sanitaria, 22(2), 151-161.

https://doi.org/10.1157/13119326

CARBON TRUST. (n.d.). JaCo - Improved Fatigue Life of Welded Jacket Connections. Retrieved from https://www.carbontrust.com/es/node/997

EWEA. (2017). Reviving wind markets and delivering on our 2030 objetives. Wind Europe. Retrieved from https://windeurope.org/wpcontent/uploads/files/policy/positionpapers/Reviving-wind-markets-anddelivering-on-our-2030-objectives.pdf

EWEA. (2019). Our Energy Our Future. Retrieved from https://windeurope.org/wpcontent/uploads/files/aboutwind/reports/WindEurope-Our-Energy-OurFuture.pdf

EWEA. (2020). Offshore Wind in Europe - Key trends and statistics 2019. https://doi.org/10.1016/s14710846(02)80021-X

Freiberg, F., \& Scholz, P. (2015). Evaluation of Investment in Modern Manufacturing Equipment Using Discrete Event Simulation. Procedia Economics and Finance, 34, 217-224. https://doi.org/10.1016/s2212-5671(15)01622-6

Gołda, G., Kampa, A., \& Krenczyk, D. (2019). The Methodology of Modeling and Simulation of Human Resources and Industrial Robots in FlexSim. In FlexSim in Academe: Teaching and Research (pp. 87-99). Springer, Cham. https://doi.org/10.1007/978-3-030-04519-7_7

Lamas-Rodríguez, A., Chas-Álvarez, D., \& MuiñaDono, J. A. (2017). Risk management in jackets manufacturing projects using discrete events simulation. 29th European Modeling and Simulation Symposium, EMSS 2017, Held at the International Multidisciplinary Modeling and Simulation Multiconference, I3M 2017, (c), 221226.

Lamas-Rodríguez, A., Crespo-Pereira, D., \& SánchezTutor, R. (2016). Discrete Events Simulation to improve manufacturing process of jackets offshore structures. 15th International Conference on Modeling and Applied Simulation, MAS 2016, (c), 85-94. Retrieved from https://pdfs.semanticscholar.org/8fof/25e11a2d9 eafb44177ce9e1785f138db1c2e.pdf

Lamas Rodríguez, A., Chas Álvarez, D., \& Muiña Dono, J. A. (2019). 3D Discrete Events Simulation to Evaluate the Internal Logistic Strategies in a Shipyard. Springer International Publishing. https://doi.org/10.1007/978-3-030-04519-7

PEMA. (2020). Welding automation for foundations. 
Adaptive robot welding. Retrieved from https://pemamek.com/welding-solutions/windenergy/offshore-wind-tower-and-foundationmanufacturing/foundations/

Salzgitter AG. (2020). Automated welding technology. Retrieved from http://www.szmr.de/en/supplyprogram/components/automated-weldingtechnology.html

Sislioglu, M., Celik, M., \& Ozkaynak, S. (2019). A simulation model proposal to improve the productivity of container terminal operations through investment alternatives. Maritime Policy and Management, 46(2), 156-177.

https://doi.org/10.1080/03088839.2018.1481544

Widjaja, L., \& Tsai, C.-F. (2019). Discrete Event Simulation for Oil Transshipment Facility. In Ports 2019: Port Planning and Development (pp. 489-499).

https://doi.org/10.1061/9780784482629.047 